\title{
SOURCE FUNCTIONS FOR AN ISOTROPICALLY SCATTERING HOMOGENEOUS SLAB BOUNDED BY A PERFECT SPECULAR REFLECTOR
}

The source function for an isotropically scattering homogeneous slab bounded by a perfect specular reflector is found using the discrete ordinate solution of the Ambartsumian-Sobolev equation.

This paper deals with the problem of finding source functions for an absorbing and isotropically scattering homogeneous slab bounded by a perfect specular reflector and illuminated by uniform parallel rays.

Let us denote the albedo for single scattering by $\lambda$ and the optical thickness of the slab by $x$. Let the angle of incidence of parallel rays be $\operatorname{arc} \cos u$. We wish to determine the source function which represents the total rate of production of scattered energy per unit volume per unit solid angle.

Let us denote the source function by $S^{*}$,

$$
S^{*}=S^{*}(t, x, u), \quad 0 \leqslant t \leqslant x, 0 \leqslant u \leqslant 1,
$$

where $t$ is the optical altitude above the reflecting bottom.

It is well known that in this case the source function satisfies the Fredholm integral equation $\left[{ }^{1}\right]$

$$
\begin{gathered}
S^{*}(t, x, u)=\frac{1}{4} \lambda\left[\mathrm{e}^{-\frac{x-t}{u}}+\mathrm{e}^{-\frac{x+t}{u}}\right]+ \\
+\frac{1}{2} \lambda \int_{0}^{x}\left[\mathrm{E}_{1}(|t-y|)+\mathrm{E}_{1}(t+y)\right] S^{*}(y, x, u) d y,
\end{gathered}
$$

where

$$
\mathrm{E}_{1}(z)=\int_{0}^{1} \mathrm{e}^{-z / w} d w / w
$$

Casti, Kagiwada and Kalaba $\left[{ }^{2}\right]$ have shown, that by formally extending of the source function to the interval $-x \leqslant t \leqslant 0$ one obtains an integral equation

$$
\begin{gathered}
S^{*}(t, x, u)=\frac{1}{4} \lambda\left[\mathrm{e}^{-\frac{x-t}{u}}+\mathrm{e}^{-\frac{x+t}{u}}\right]+ \\
+\frac{1}{2} \lambda \int_{-x}^{x} \mathrm{E}_{1}(|t-y|) S^{*}(y, x, u) d y
\end{gathered}
$$


where the symmetry relation

$$
S^{*}(-t, x, u)=S^{*}(t, x, u)
$$

has been used. Comparing equation (2) with the integral equation for the standard case, i. e., when there is no reflecting bottom at $t=0$,

$$
S(t, x, u)=\frac{1}{4} \lambda \mathrm{e}^{-\frac{x-t}{u}}+\frac{1}{2} \lambda \int_{0}^{x} \mathrm{E}_{1}(|t-y|) S(y, x, u) d y,
$$

one can see that the following relationship holds $\left[{ }^{2}\right]$

$$
S^{*}(t, x, u)=S(x+t, 2 x, u)+S(x-t, 2 x, u) .
$$

This important relationship gives us the possibility of expressing the source function for the problem of a perfect specular reflector by means of the solution of the standard problem. We have found a semi-analytic solution to the standard problem [ $\left.{ }^{3}\right]$ (if only $\lambda \neq 1$ ) in the form

$$
S\left(t, x, u_{i}\right)=\frac{1}{2} \lambda u_{i} \sum_{n=1}^{N} A_{n}\left[\frac{U_{i n} \mathrm{e}^{-\beta_{n}(x-t)}}{1-\beta_{n} u_{i}}+\frac{V_{i n} \mathrm{e}^{-\beta_{n} t}}{1+\beta_{n} u_{i}}\right],
$$

where

$$
\begin{aligned}
& U_{i n}=X\left(u_{i}, x\right)-Y\left(u_{i}, x\right) C_{n}, \\
& V_{i n}=X\left(u_{i}, x\right) C_{n}-Y\left(u_{i}, x\right),
\end{aligned}
$$

and

$$
C_{n}=-\frac{G_{n}}{1-D_{n}} .
$$

Here $X$ and $Y$ are the well-known Ambartsumian-Chandrasekhar functions.

The functions $G_{n}$ and $D_{n}$ are defined by the following formulae

$$
\begin{aligned}
& D_{n}=\frac{1}{2} \lambda \sum_{m=1}^{N} \frac{a_{m} X\left(u_{m}, x\right)}{1+\beta_{n} u_{m}}, \\
& G_{n}=\frac{1}{2} \lambda \sum_{m=1}^{N} \frac{a_{m} Y\left(u_{m}, x\right)}{1+\beta_{n} u_{m}},
\end{aligned}
$$

and $\beta_{n}$ are the roots of the characteristic equation

$$
1-\lambda \sum_{m=1}^{N} \frac{a_{m}}{1-\beta^{2} u_{m}^{2}}=0
$$

The $a_{i}$ and $u_{i}$ are the weights and the points of the gaussian quadrature formula of order $N$, normalized to the interval $(0,1)$, and $A_{n}$ are the coefficients to be determined from the boundary conditions

or

$$
S\left(0, x, u_{i}\right)=\frac{1}{4} \lambda Y\left(u_{i}, x\right),
$$

$$
S\left(x, x, u_{i}\right)=\frac{1}{4} \lambda X\left(u_{i}, x\right) .
$$

Using equation (6) in equation (5), we get immediately 
$S^{*}\left(t, x, u_{i}\right)=\frac{1}{2} \lambda u_{i} \sum_{n=1}^{N} A_{n}\left[\mathrm{e}^{-\beta_{n}(x+t)}+\mathrm{e}^{-\beta_{n}(x-t)}\right]\left(\frac{U_{i n}}{1-\beta_{n} u_{i}}+\frac{V_{i n}}{1+\beta_{n} u_{i}}\right)$.

One must be careful in using formula (12) since the quantities $A_{n}, U_{\text {in }}$ and $V_{i n}$ are to be determined for the slab of optical thickness $2 x$.

For comparison we have calculated the reflection function for the case $x=0.1$ and $\lambda=0.9$ using equation [ $\left.{ }^{4}\right]$

$$
\begin{gathered}
\frac{\partial}{\partial x} R(v, u, x)= \\
=-(1 / u+1 / v) R(v, u, x)+\lambda\left[1-1-\mathrm{e}^{-2 x / u}+\frac{1}{2} \int_{0}^{1} R(w, u, x) d w / w\right] \times \\
\times\left[1+\mathrm{e}^{-2 x / v}+\frac{1}{2} \int_{0}^{1} R(v, w, x) d w / w\right],
\end{gathered}
$$

$R(v, u, 0)=0$.

In this equation $\operatorname{arc} \cos v$ is the angle of reflection. It should be mentioned that here the normalization of the reflection function differs slightly from the one used in $\left[{ }^{4}\right]$.

On the other hand, we have obtained the reflection function by using the source function $\left[{ }^{4}\right]$

$$
R(v, u, x)=4 \int_{0}^{x} S(y, x, u)\left[\mathrm{e}^{-\frac{x-y}{v}}+\mathrm{e}^{-\frac{x+y}{v}}\right] d y .
$$

In formula (14) the source function has been found according to the techniques described above. For numerical integration the Simpson rule has been used. The results are shown in the Table. In general, at least

\begin{tabular}{|c|c|c|c|c|c|c|}
\hline \multirow{2}{*}{$\arccos u_{i}$} & \multicolumn{2}{|c|}{$R\left(v_{1}, u_{i}, x\right)$} & \multicolumn{2}{|c|}{$R\left(v_{4}, u_{i}, x\right)$} & \multicolumn{2}{|c|}{$R\left(v_{7}, u_{i}, x\right)$} \\
\hline & Eq. (14) & Eq. (13) & Eq. (14) & Eq. (13) & Eq. (14) & Eq. (13) \\
\hline $88^{\circ} .54$ & 0.013232 & 0.013232 & 0.048669 & 0.048669 & 0.053209 & 0.053209 \\
\hline $82^{\circ} .57$ & 0.031826 & 0.031826 & 0.196845 & 0.196846 & 0.215872 & 0.215872 \\
\hline $72^{\circ} .72$ & 0.043324 & 0.043324 & 0.281847 & 0.281847 & 0.309162 & 0.309162 \\
\hline $60^{\circ}, 00$ & 0.048669 & 0.048669 & 0.319242 & 0.319243 & 0.350195 & 0.350195 \\
\hline $45^{\circ} .34$ & 0.051279 & 0.051279 & 0.337119 & 0.337119 & 0.369808 & 0.369809 \\
\hline $29^{\circ} .45$ & 0.052601 & 0.052601 & 0.346089 & 0.346090 & 0.379650 & 0.379650 \\
\hline $12^{\circ} .95$ & 0.053209 & 0.053209 & 0.350195 & 0.350195 & 0.384154 & 0.384154 \\
\hline
\end{tabular}
five significant figures of agreement have been found.

Comparison of two calculations for the diffuse reflection function $(x=0.1, \lambda=0.9)$ $N=7$

Summarizing we can say that our results may prove useful in the interpretation of radiation measurements, since the air - sea interface may be considered a specular reflector in the ultraviolet region $\left[{ }^{2}\right]$.

\section{REFERENCES}

1. Соболев В. В., Перенос лучистой энергии в атмосферах звезд и планет, М., 1956, 391 c.

2. Casti, J., Kagiwada, H., Ka laba, R., J. Quant. Spectroscopy and Radiat. Transfer, 13, No. 3, 267 (1973). 
3. В и йк Т., Публикации Тартуок. астрофиз. обсерв. им. В. Струве, 44, 72 (1976).

4. C a st i, J. L., K a l a b a, R., U e n o, S., J. Quant. Spectroscopy and Radiat. Transfer, 9, No. 5, 537 (1969).

$\begin{array}{cc}\text { Academy of Sciences of the Estonian SSR, } & \text { Received } \\ \text { Institute of Astrophysics and } & \text { Sept. 15, } 1976 \\ \text { Atmospheric Physics } & \end{array}$

T. VIIK

\section{ALLIKFUNKTSIOON IDEAALSE PEEGELDAJAGA PIIRNEVA HOMOGEENSE, ISOTROOPSELT HAJUTAVA KIHI JAOKS}

Allikfunktsiooni leidmiseks on kasutatud Ambartsumjan-Sobolevi võrrandi diskreetsete ordinaatide meetodil saadud lahendit.

T. ВИИК

\section{ФУНКЦИЯ ИСТОЧНИКА ДЛЯ ИЗОТРОПНО РАССЕИВАЮЩЕГО ОДНОРОДНОГО СЛОЯ, ГРАНИЧАЩЕГО С ИДЕАЛЬНОИ ЗЕРКАЛЬНОИ ПОВЕРХНОСТЬЮ}

Для нахождения функции источника использовано решение уравнения Амбарцу. мяна-Соболева для альбедной задачи. 